\title{
Corporate Social Responsibility \\ and Its Reporting From a Management \\ Control System Perspective
}

Edward T. Vieira, Jr.

Simmons University, USA

edward.vieira@simmons.edu

Susan Grantham

University of Hartford, USA

grantham@hartford.edu

Susan D. Sampson

Simmons University, USA

susan.sampson@simmons.edu

Corporate social responsibility (CSR) is a response to stakeholder concerns and signals organisational legitimacy. We propose CSR reporting from a comprehensive and integrated management control system perspective. Reporting parameters start with stated people, planet, and profit goals supported by objectives achieved through legal, ethical/moral, economic, and giving practices. Objectives are measured, assessed, and reported through key performance indicators. These objectives are quantified, sufficiently specific, have a timeline, and identify targeted stakeholder group(s). CSR strategy and its reporting are consistent with organisational mission, values, and strategy. CSR, like most business processes, is a dynamic process occurring over time and adjusting to circumstances sometimes involving trade-offs. CSR reporting ideally reflects this process through providing context and visual depictions of goals, practices, and performance evaluation that demonstrate not only a single period in time, but also trends that may present a more complete picture of an organisation's CSR performance. CSR reporting parameters are proposed.

Key Words: CSR disclosure, CSR reporting, CSR Management Control System, CSR performance evaluation

JEL Classification: M14, M31, M37, M30, M16

(c) Br.sA https://doi.org/10.26493/1854-6935.19.127-144

\section{Introduction}

If a corporate social responsibility (CSR) message is to be effective, it must be viewed as credible. Credibility starts with the message source and then 
extends to the message, eventually developing a bidirectional, transactional relationship of influence between sender and receiver. What makes a message credible starts with it being believable. And, what makes a believable source is related to previous and current actions as well as message content. In the case of this paper, the source is the organisation and the message is its CSR reporting. We broadly use the term organisation as representing corporations, companies, firms, non-profits, and governmental entities.

Credibility stems from perceived trust and competence (Vieira 2019), which are closely related. Both must be present to achieve credibility, and the exercise of competence lays the groundwork for trust. Trust comes when promises are delivered and when shortfalls are disclosed in a spirit of transparency. When communicating with key stakeholders about their concerns, having credibility goes a long way to facilitate and maintain goodwill and legitimacy with them. Credibility is about stakeholders believing that CSR efforts are responsive to their expectations, sincere, and effectively contribute to the betterment of humanity in some way.

Our proposed reporting parameters centre on organisations who have the resources required to develop and implement a comprehensive CSR plan. These types of organisations have management control systems (MCs) in place to operate, manage, and evaluate various aspects of operations, including the execution of CSR plans. An MCs provides a comprehensive and integrated system that offers the opportunity to efficiently and effectively manage ongoing and dynamic processes in proactive and reactive ways relevant to environmental conditions (Winkler 2010). An MCs assures a systematic and effective approach to achieving optimal and sustainable results.

CSR as a major functional contributor to corporate mission faces two major challenges, partly owing to the lack of Mcss and the challenges of integrating the many stakeholder interests into a unified system that is part of, and consistent with, the overall business strategy as are other functional and divisional areas such as finance, sales, manufacturing, supply chain management, operations management, information technology, human resources, international divisions, and so forth. Their internal nature places them at the discretion of management. First, CSR is a response to external as well as internal stakeholders' concerns and expectations, which can come into conflict with internal as well as external parties such as community stakeholders advocating for a companysupported costly social program that may not yield any direct or imme- 
diate benefits to the organisation. Second, there is the nature and level of disclosure. CSR is presented as an annual report available to the general public accessible via a website. Stakeholder reactions to the annual CSR report make management particularly concerned about what is presented and to what degree. Although there has been pressure for CSR disclosure to provide more relevant information (Bonson and Bednarova 2015; Lock 2015), many reports continue to present goals and 'good deed' practices, with little emphasis on the degree to which goals and benchmarked objectives have been achieved within a given timeline.

We propose a comprehensive, practical, and Mcs-based framework for reporting CSR that meets stakeholders' expectations. Utilising this framework to report CSR presupposes the deployment of MCS in CSR and requires an understanding of CSR in the operational context of MCS. We begin with a review of the literature, focusing on what has been done with CSR-MCS in practice and what has not been researched. We then describe our proposed CSR-MCS reporting framework in sufficient detail including the steps required to implement this system.

\section{Review of Related Literature}

Although most publicly traded corporations voluntarily disclose CSR activities, the lack of comprehensiveness, consistency, standards, and quality of reporting has been called into question (Albertini 2019; Bouten et al. 2011; Font et al. 2012; Lock 2015). Many companies fall far short of disclosure requirements recommended by third-party organisations like GRI, ISO, and others (Escrig-Olmedo, Fernandez-Izquierdo, and MunozTorres 2010; Hickman and Cote 2019).

Research suggests that the lack of comprehensiveness and transparency reporting might be owing to management's undue influence on disclosure (Bonson and Bednarova 2015), the perception that stakeholders want or should be given concrete and straightforward content that is easily processed (Arjalies and Mundy 2013; Coombs and Holladay 2009; Crilly, Ni, and Jiang 2016), the focus on financial and accounting metrics, emphasis on prioritised stakeholders (Arvidsson 2010; Costa and Torrecchia 2018; Escrig-Olmedo, Fernandez-Izquierdo, and Munoz-Torres 2010), and pending legal actions (DeTienne and Lewis 2005).

Additionally, because of trade-offs and decisions involving short-term (within the CSR annual reporting cycle) cost for uncertain long-term gain, sustainability is a challenge for some CSR-related efforts (Feder and Weibenberger 2019; Hahn et al. 2010). The benefit is often viewed as ab- 
stract and uncertain, unlike the immediacy of short-term gains, which are concrete, easily presented, and perhaps, in part, why simply reporting practices and good deeds are appealing and often disclosed (Hopwood 2009).

In addition to the dearth of comprehensive CSR disclosure, research in this area has focused on the benefits of CSR reporting, the different levels and nature of practices relevant to stakeholders' varied expectations, differences in management's agenda, the interaction between stakeholders and management, and general descriptions of CSR efforts (Gond et al. 2012; Herremans and Nazari 2016; Laguir, Laguir, and Tchemeni 2019; Schonher, Findler, and Martinuzzi 2017). Moreover, the research on reporting CSR from a MCS perspective is virtually non-existent, with emphasis on general constructs (Rinawiyanti, Huang, and As-Saber 2020).

Yet, research deploying and integrating CSR into control systems, and reporting their efforts and outcomes is important in an ever increasingly complex world (Battaglia et al. 2016). Consequently, this paper proposes a sufficiently detailed and integrated MCs approach for reporting CSR which offers an opportunity for transparency and for contributing to the credibility of the reporting organisation in the eyes of its stakeholders. This framework presupposes the existence of an operating CSR MCs. Without such a system, sufficiently full and transparent CSR disclose cannot take place. Our framework offers reporting details including types of sustainable cSR goals available, types of benchmarked objectives established that serve as the basis for outcome assessment, and categories of CSR practices utilized to attain goals. Reporting these components presents a detailed, comprehensive, and transparent picture of an organisation's good faith CSR efforts.

\section{What is CSR?}

We start with a conceptual definition. Then, we discuss operational CSR parameters, which are the basis for reporting because they serve as concrete evidence of an organisation's effort and performance at meeting stakeholders' expectations.

\section{CONCEPTUALLY, WHAT IS CSR?}

We define CSR as: 'organisational actions that take into account stakeholders' expectations concerning economic, social, and environmental performance' (Aqueveque, Rodrigo, and Duran 2018, 223). This process extends from the short-term to sustainable long-term. These expecta- 
tions require controls necessary to reach, maintain, and adjust them accordingly (Deegan 2002; Hickman and Cote 2019). The process facilitates favourable perceptions from relevant stakeholders. To sustain these efforts and favourable outcomes requires the flexibility to address shifting priorities, the availability of resources, trade-offs such as short-term cost for long-term benefit situations (Johnstone 2018; Munoz-Torres et al. 2009), competing and changing stakeholders' interests, realigning organisational culture, changing leadership, and a host of other internal and external conditions (Hooghiemstra 2000; Jahdi and Acikdilli 2009).

CSR is an organisation's response to address stakeholders' concerns, which involves reporting efforts and performance outcomes. Stakeholders are individuals, groups, and/or organisations who are affected by the organisation's operations and/or who can affect the organisation's operations (Freeman 1984; Parmar et al. 2010).

Stakeholders can be classified as primary or secondary (Metcalfe 1998). Primary stakeholders are those parties without whose continued participation the organisation could not survive. Secondary stakeholders are those parties whose interaction is not required for the organisation to survive. Additionally, research suggests that not all stakeholders are equal (Johnstone 2018) and that some are valued more depending on the industry or sector. In the food, pharmaceutical, and energy industries, Shnayder and Rijnsoever (2018) found such differences. Gubova et al. (2017) discovered differences in prioritising stakeholders among metallurgical/glass building, printing, food business, and machinery industries. Aqueveque, Rodrigo, and Duran (2018) found that stakeholders stemming from an organisation's core business were valued more especially if this involves some essential aspect of regular operations. Findings of a study by Cooper et al. (2001) suggest that those organisations that directly interact with individual consumers tend to focus their CSR attention on customer stakeholders. Sweeney and Coughlan's (2008) CSR reporting research of the financial services, medical pharma, health and beauty pharma, telecommunications, automobile, oil and gas, and retail industries discovered references to corporate responsibilities directed at a variety of stakeholders that varied across sectors.

\section{OPERATIONALLY, WHAT IS CSR?}

How CSR moves from an aspirational idea to reality requires an organised system in place that guides and controls the process and activities, and provides for continuous feedback so that the implementation of CSR 
is adjusted and sustained in accordance with ultimate goals. In other words, the idea of CSR becomes concrete and measurable once it is operationalised.

This system is an MCs. MCss are formal and informal structures, including practices and reporting, put in place by a business to compare the goals and strategy of the organisation against the actual outcomes both nonfinancial and financial on an ongoing basis. This comparison is then reviewed and used to drive managerial decisions across multiple levels of the organisation (Arjalies and Mundy 2013; Cresti 2009).

If CSR reporting is to be transparent and legitimate in the eyes of stakeholders, not only goals and good deeds must be reported, but performance outcomes as well. Outcomes that meet expectations as well as those that fall short must be disclosed. In sum, it is a matter of what the company intends to do, how it will do it, and whether the company did itall critical to comprehensive and transparent CSR (Costa and Torrecchia 2018; Johnstone 2018).

Reporting centred on comprehensive and MCs-based CSR requires not only the operation of such a system, but a clear understanding of it. Therefore, borrowing from MCs principles, the following covers our proposed reporting framework, including the steps required for reporting and an illustration.

- Goals. These are what we hope to attain or achieve and can be general or fairly specific (Vieira 2019). In principle, CSR goals are reached through ethical operating practices that meet socially meaningful standards and stakeholder expectations in a manner consistent and supportive of the organisational mission and business strategy. Sustainable CSR occurs at the intersection of People, Planet, and Profit goals (Carroll 1991; 2016; Elkington 1994).

- People. This type of goal involves adding value to individuals' lives and contributing to society in different ways. Contributions include providing jobs and training; offering safe working conditions; paying taxes used to support society; developing innovations, including technologically-based; and offering attractive healthcare benefits, family leave policies, and desirable pension options.

- Planet. Environmental goals involve the maintenance of natural environmental capital (Goodland 1995) addressing both conservation and pollution mitigation. Some areas of attention are global warming, green engineering and chemistry, air and water quality, alterna- 
tives to depleting natural resources, ecosystems, resource integrity, and addressing pollutants.

- Profit. Economic goals focus on sustainable financial and economic viability such as profit, maintaining cash flow, paying taxes, raising capital, providing cost-effective and competitively priced goods and services, supply chain integrity, and offering attractive owners' equity. Profit goals focus on business strategy and mission, integrating CSR (Massung et al. 2013; Parmar et al. 2010). In sum, CSR captures the way business affects and is affected by the social, economic, and environmental expectations of stakeholders (Coombs and Holladay 2009).

\section{CSR Objectives: The Basis for Performance Evaluation}

Objectives are the means by which we assess CSR goal outcomes (Vieira 2019). They serve two purposes. First, if aligned effectively, they guide the development of implementation practices designed to reach them, which in turn lead to goal achievement. Second, they serve as the basis for measurement and performance evaluation (Ferreira and Otley 2009).

Objectives have four parts. First, an objective must be sufficiently specific. For example, an objective may be to reduce the release of sulphur dioxide into the atmosphere. Second, it must be quantifiable. For instance, an objective may be to reduce by 10 metric tonnes the release of sulphur dioxide into the atmosphere. Alternatively, it might be framed as to reduce the release of sulphur dioxide by $10 \%$ from the previous year. Third, an objective requires a timeline. For example, during 2021, sulphur dioxide release into the atmosphere will be reduced by 10 metric tonnes. Last, if the objective targets specific stakeholders, then the group(s) must be described along with the objective. In other words, identify the key stakeholder group(s) who can impact and/or who are impacted by the CSR objective.

Objectives are categorised variously; we focus on the types appropriate for a CSR MCs, which are interim and summative. Interim measures reflect the ongoing nature of the evaluation process because MCs is dynamic and adjusts to various conditions. Activities and outcomes are monitored, diagnosed and assessed, and deviations are corrected (Simons 2006) on an ongoing basis during the course of CSR operations. It is important for those who develop the annual CSR report to understand this type of monitoring because under- or overperformance in a given period may impact an annual assessment. Thus, interim assessments may serve 
to provide an evidenced-based explication supporting revised planning moving forward. Second, there are summative objectives, which are the final measurement of objectives, used to determine whether an annual goal is achieved. Each goal has at least one corresponding performance objective. Goals or objectives can be weighted as part of a total evaluation system based on organisational and stakeholder priorities.

The specific tools deployed to measure performance outcomes are key performance indicators (KPIS). Typically, a number of KPIS measure an objective. Creating K PIS for an objective requires an understanding about what constitutes a specific objective, how to measure it, and what is required to achieve it.

\section{CSR EVALUATION}

The degree to which benchmarked objectives are met can be rated and reported as outstanding, excellent, very good, good, average, and below standard. The specific numeric reference points are set by the company. They are measured deploying KPIs. Interim measurement of benchmarked objectives using KPIS are used to monitor and assure that CSR is executed as planned and with desired outcomes to date.

The degree to which performance objectives and their KPIS fall within an acceptable range is their tolerance (Collier and Evans 2017). They vary per objective and KPIs. All objectives must rest within their tolerances to be considered successful. As part of the internal assessment, the overall plan requires that a specified percentage of KPIS assigned to the objective have outcomes within tolerances, including all of the prioritized KPIS. This holds true for interim and summative measurements as well. If all or a percentage number of KPI reach their own tolerances, then the objective has been met. If all objectives are met, then the CSR goal has been reached. Although there is no general consensus on a standard method for reporting KPIS (Bouten et el. 2011; Escrig-Olmedo, Fernandez-Izquierdo, and Munoz-Torres 2010), some third-parties provide reporting systems that measure, capture, and evaluate CSR outcomes such as GRI, Iso, Dow Jones, A A 1000, Caux Round Table Principles, Domini 400, eiris, emas, Ethical Trading Initiative, F TSE4 Good Index, and Global Compact (Bonson and Bednarova 2015).

\section{CSR IMPLEMENTATION PRACTICES}

To achieve objectives requires the deployment of CSR implementation practices, which include static or ongoing tasks and activities. The follow- 
ing describes the four types of CSR practices: economical, legal, ethical, and philanthropical.

- Economic. In order to be economically viable and sustainable over the long-term, corporations earn profits through economic activities. Their financial performance can enhance or diminish their capacity to maintain cash-flow, meet shareholder expectations, raise capital for expansion, institute upgrades, conduct research and development, and support other activities or capabilities necessary to be competitive and thrive.

- Legal. Society expects and the law requires businesses to pursue profitable activities lawfully. Think of these legal expectations as codified ethics. Violations of laws, whether civil or criminal, whether intentional or not, damage not only corporate image, but the trust stakeholders place in an organisation.

- Ethical. These practices in business start by discerning what is good or right (contributing to human flourishing), as opposed to that which is bad or wrong (contributing to human impoverishment). Ethics is what guides the conduct of professional activities informed by normative moral values and beliefs consistent with an organisation's mission and values statements (Du, Bhattacharya, and Sen 2010; Vieira 2019). Ethics can fill the gap not addressed by laws.

- Philanthropic. Giving practices include all types of giving such as monetary, scholarships, grants, fundraising, products and services in kind, volunteerism by employees, sponsorship of prosocial cause events, and many more types of discretionary giving. Iв M's On Demand Community Initiative, Microsoft and the Gates Foundation, Gilead Sciences, and Walmart have robust giving programmes. Some philanthropy relates to a corporation's core business while other forms of giving do not (Quelch 2004).

\section{A Proposed CSR Reporting System}

The annual corporate CSR report's audiences are stakeholders and the general public. Details of what is presented can be explored in specialty and more comprehensive reports geared toward different aspects of CSR and specific stakeholders such as third-party reporting agencies, the annual report, environmental disclosures, and SEC filings.

We propose a format that is both sufficiently comprehensive and pragmatic that includes CSR goals, highlighted key practices to reach goals, 
and performance evaluation including summative objectives, tolerances, and ratings. Because of the sustainable nature of CSR, relevant economic data should be presented in the report to demonstrate financial viability over the longer term.

Disclosure of the previous year's CSR efforts would include the following steps:

1. Present the CSR goals.

2. Highlight key practices deployed to achieve the CsR goal.

3. Report the performance objectives required to assess the goal, which might relate to

4. Employ more than one type of assessment such as financial impact. Evaluation may be addressed along with the outcomes as noted in the next one or two steps.

5. Indicate the quantitative outcomes for the targeted timeframe.

6. If informative and adds value, present the corresponding benchmarked tolerances.

7. Cite K PIS if they are exemplars of practices that achieve goals.

8. Provide an assessment term, which may be presented in the narrative such as 'Excellent' or 'Poor' outcome.

9. If appropriate, reference the primary stakeholders for the presented CSR initiative.

These steps provide a systematic guide. Individual situations may vary; however, effectively responding to stakeholder expectations in a credible and transparent manner is critical. For efficacious communication, a clear understanding of the target audience and their expectations is required. Framing the required information in an engaging manner is also part art and part craft.

The example in table 1 illustrates how the components are interrelated and is meant to serve as an internal document designed to capture the information required for CSR disclosure. The reporting format can vary because of organisational circumstances, whether it is presented in a table, infographic, and/or narrative; however, for the most part, the same information would be disclosed. This approach provides a level of comprehension so that the reader understands what the organisation did, how it did it, and whether it met its goal (Lydenberg, Rogers, and Wood 2020).

In this example, the year reported is 2020 . The goal is to convert $25 \%$ of the corporate fleet to fuel efficient vehicles over a five-year period start- 


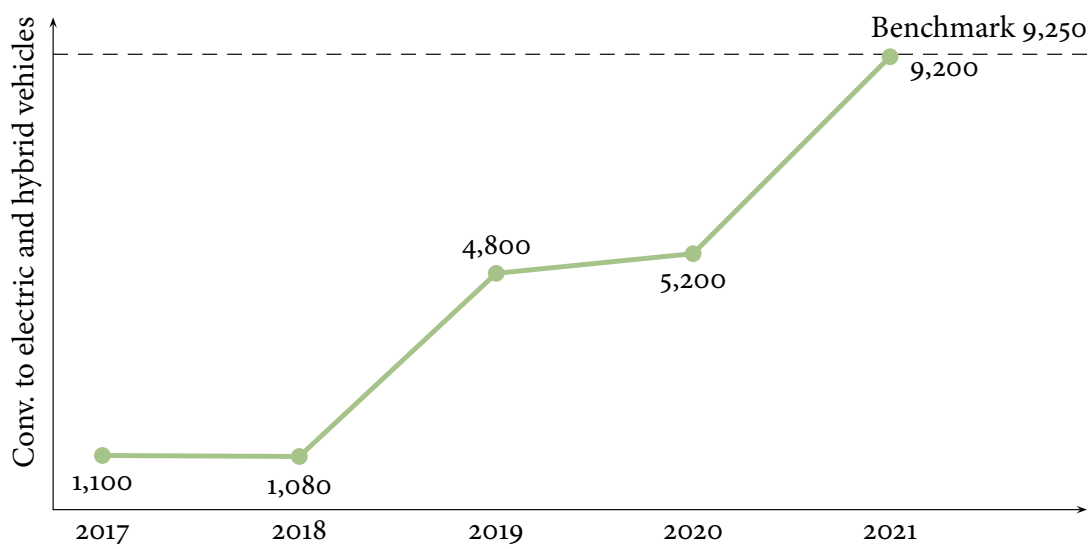

FIGURE 1 Years 2017-2021 Trendline to Convert 25\% of 37,00o Fleet to All-Electric and Hybrid Vehicles

ing 1 January 2020. The bold numbers represent the year-end figures. This will be achieved through two benchmarked performance objectives: converting $3 \%$ of the fleet to electric vehicles and $2 \%$ of the fleet to hybrid vehicles by the end of 2020 with acceptable ranges or tolerances being $2.50-3.00 \%$ and $1.75-2.00 \%$ respectively by the year's end. The actual outcomes were $2.75 \%$ and $2.00 \%$, respectively. These outcomes are rated 'Very Good' and 'Excellent,', respectively.

Although the goal focuses on the replacement of fossil fuel powered vehicles with electric/hybrid vehicles, it is relevant to the environment and thus includes impact data. The financial component speaks to sustainability. As we can see, carbon dioxide emissions were reduced by 2021.13 metric tonnes by the end of the first year. Cost savings were $\$ 935,000$ for the same period. Of course, the ultimate longer-term goal is to reduce air pollution in a cost-efficient manner. Last, a list of primary stakeholders is included.

Although reporting focuses on annual plans and outcomes, much of the effort can be understood more clearly over time relevant to long-term goals, which can be subject to business, market, social, and economic cycles that impact social, environmental and financial ro I (McLymont 2018; Nayak and Patjoshi 2020). For this reason, sometimes trendline depictions convey a clearer longer-term picture of CsR performance. As seen in figure 1, visuals trending positively can be represented through the presentation of graphs and charts. As the adage goes, 'A picture is worth a thousand words' (Speziale and Kloviene 2014). 


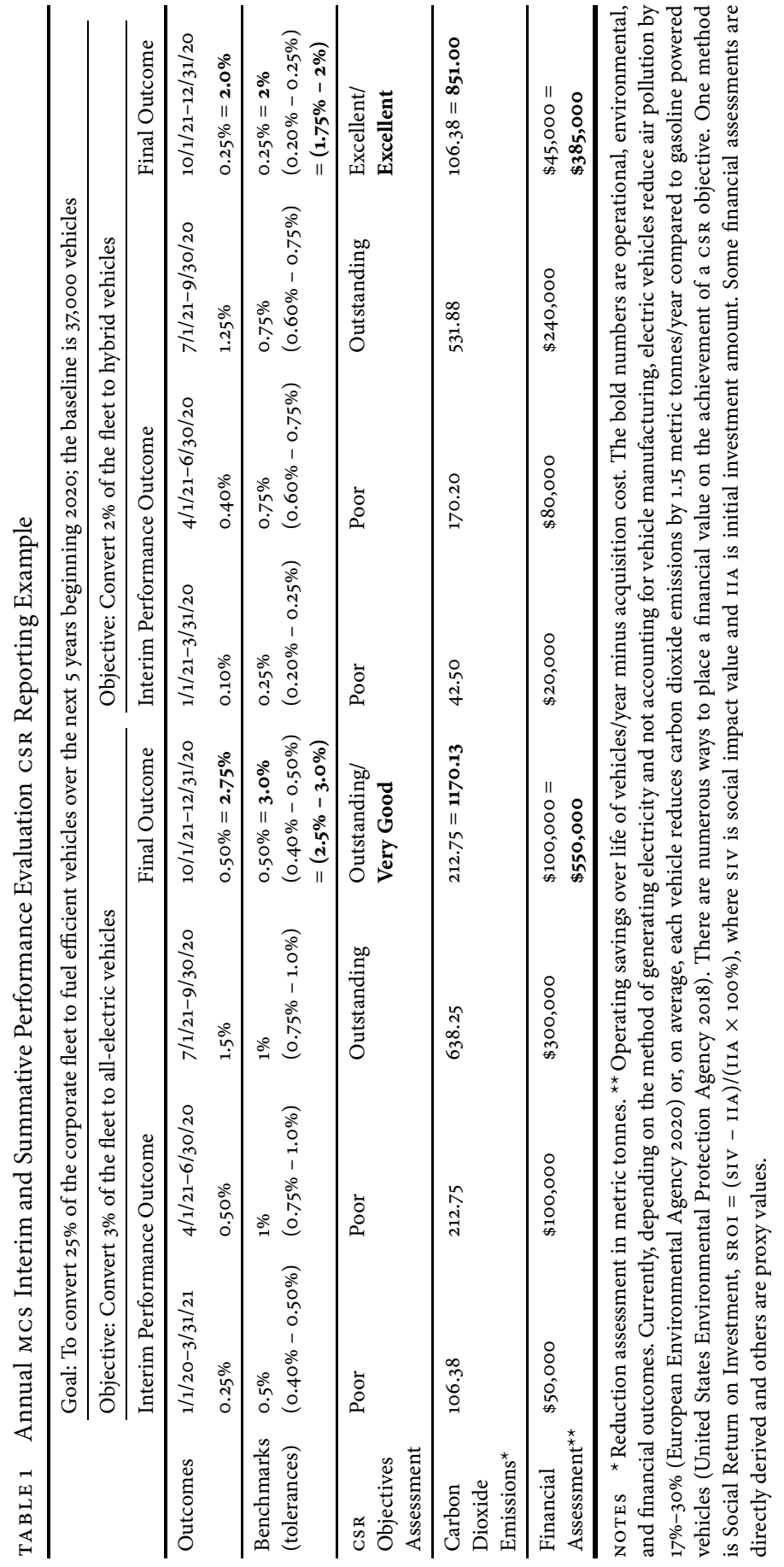


There are a number of other considerations worth mentioning. First, although the above approach provides a common set of general parameters for inclusion in an annual CSR report, each organisation within an industry has a set of unique conditions to various degrees that may require a different component to CSR reporting. Second, outcomes can be measured in financial, and often in other CSR related, metrics. These mixes vary. For instance, financial metrics can be standardised to some measure of ROI, contribution to the bottom line, sales, or some combination of performance measures (McLymont 2018; Nayak and Patjoshi 2020). Nonfinancial measures can be reported as specific reduction of pollutants, educating workforce rates, unit or percentage changes, percentages of a diverse workforce, and so forth. Third, the fourth component of an objective is the identification of the impacted stakeholder group(s). This is essentially an internal consideration and any mention of them in the official annual CSR report would be arbitrary. Last, some organisations have elected to report goals and their assessment in terms of KPIS that are relatable to readers, which would contribute to transparency providing that they are a true representation of outcome evaluation and understandable in terms of the CsR goal.

\section{Conclusion}

Stakeholders, both internal and external, want to know about CSR efforts (Arjalies and Mundy 2013). Unless interested parties are aware of the organisation's response to their concerns, the company's credibility, legitimacy, commitment, and level of stakeholder engagement may be called into question (Arjalies and Mundy 2013; Bacinello, Tontini, and Alberton 2020; Stojanovic et al. 2020). Communicating CSR goals, practices, and outcomes can affect a company's productivity and bottom-line through such influences as the auto-communication effect (Hagen 2008; Spence 2009) where an organisation's messaging about CSR initiatives encourages employees and other internally-related stakeholders such as vendors and suppliers to engage with the organisation, and reinforce a culture of ethical and social responsibility. In sum, effective CSR reporting not only informs, but serves to inspire.

Yet, few large corporations comprehensively deploy MCs for CSR. In reality, planning components are often disjointed and staggered at best (O'Riordan 2010). Scholars acknowledge the importance of a dynamic and integrated approach to CSR that includes business strategy and consistent CSR practices in collaboration with stakeholders in an environ- 
ment that requires adjustment over time owing to trade-offs (Winkler 2010). This can make performance evaluation a moving target (Morsing and Schultz 2006) and may be a significant reason why many organisations with limited resources struggle with the reporting process, resulting largely in the disclosure of aspirational and select good deeds (Hopwood 2009). Understanding this process will aid organisations in their journey toward reporting CSR that is transparent and comprehensive.

\section{References}

Albertini, E. 2019. 'The Contribution of Management Control Systems to Environmental Capabilities.' Journal of Business Ethics 159:1163-80.

Aqueveque, C., P. Rodrigo, and I. J. Duran. 2018. 'Be Bad But (Still) Look Good: Can Controversial Industries Enhance Corporate Reputation through CSR Initiatives.' Business Ethics: A European Review 27:22237.

Arvidsson, S. 2010. 'Communication of Corporate Social Responsibility: A Study of the Views of Management Teams in Large Companies.' Journal of Business Ethics 96:339-54.

Arjalies, D. L., and J. Mundy. 2013. 'The Use of Management Control Systems to Formulate and Implement CSR Strategy: A Levers of Control Perspective.' Management Accounting Research 24 (4): 284-300.

Bacinello, E., G. Tontini, and A. Alberton. 2020. 'Influence of Maturity on Corporate Social Responsibility and Sustainable Innovation in Business Performance.' Corporate Social Responsibility and Environmental Management 27 (2): 749-59.

Battaglia, M., E. Passetti, L. Bianchi, and M. Frey. 2016. 'Managing for Integration: A Longitudinal Analysis of Management Control for Sustainability.' Journal of Cleaner Production 136 (A): 213-25.

Bonson, E., and M. Bednarova. 2015. 'CSR Reporting Practices of Eurozone Companies.' Spanish Accounting Review 18 (2): 182-93.

Bouten, L., P. Everaert, L. Van Liedekerke, L. De Moor, and J. Christiaens. 2011. 'Corporate Social Responsibility Reporting: A Comprehensive Picture.' Accounting Forum 35 (3): 187-204.

Carroll, A. B. 1991. 'The Pyramid of Corporate Social Responsibility: Toward the Moral Management of Organisational Stakeholders.' Business Horizons 34 (4): 39-48.

- 2016. 'Carroll's Pyramid of Corporate Social Responsibility: Taking Another Look.' International Journal of Corporate Social Responsibility $1(3): 1-8$.

Collier, D. A., and J. R. Evans. 2017. oм6 Operations and Supply Chain Management. Boston, MA: Cengage Learning. 
Coombs, T. W., and S. J. Holladay. 2009. 'Corporate Social Responsibility: Missed Opportunity for Institutionalizing Communication Practice.' International Journal of Strategic Communication 3 (2): 93-101.

Cooper, S., D. Crowther, M. Davies, and K. Davis. 2001. Shareholder or Stakeholder Value: The Development of Indicators for the Control and Measurement of Performance. London: The Chartered Institute of Management Accountants.

Costa, M., and P. Torrecchia. 2018. 'The Concept of Value for CSR: A Debate Drawn from Italian Classical Accounting. Corporate Social Responsibility and Environmental Management 25:113-23.

Cresti, E. 2009. 'Sustainability Management Control Systems: Towards a Socially Responsible Planning and Control Framework.' Paper presented at the Oxford Business and Economics Conference, Oxford, 24-6 June.

Crilly, D., N. Ni, and Y. Jiang. 2016. 'Do-No-Harm versus Do-Good Social Responsibility: Attributional Thinking and the Liability of Foreignness.' Strategic Management Journal 37 (7): 1316-29.

Deegan, C. 2002. 'Introduction: The Legitimising Effect of Social and Environmental Disclosures: A Theoretical Foundation.' Accounting, Auditing and Accountability Journal 15 (3): 282-311.

DeTienne, K. B., and L. W. Lewis. 2005. 'The Pragmatic and Ethical Barriers to Corporate Social Responsibility Disclosure: The Nike Case.' Journal of Business Ethics 60:359-76.

Du, S., C. B. Bhattacharya, and S. Sen. 2010. 'Maximizing Business Returns to Corporate Social Responsibility (CSR): The Role of CsR Communication.' International Journal of Management Review 1:8-19.

Elkington, J. 1994. Cannibals with Forks: The Triple Bottom Line of 21st Century Business. Oxford: Capstone.

Escrig-Olmedo, E., M. Fernandez-Izquierdo, and M. Munoz-Torres. 2010. 'Socially Responsible Investing: Sustainability Indices, E S G Rating and Information Provider Agencies.' International Journal of Sustainable Economy 2 (4): 442-61.

European Environmental Agency. 2020. 'EE A Report Confirms: Electric Cars are Better for Climate and Air Quality. https://www.eea.europa .eu/highlights/eea-report-confirms-electric-cars.

Feder, M., and B. E. Weibenberger. 2019. 'Understanding the Behavioural Gap: Why Would Managers (Not) Engage in CsR-Related Activities.' Journal of Management Control 30:95-126.

Ferreira, A., and D. Otley. 2009. 'The Design and Use of Performance Management Systems: An Extended Framework for Analysis.' Management Accounting Research 20:263-82.

Font, X., A. Walmsley, S. Cogotti, L. McCombes, and N. Hausler. 2012. 
'Corporate Social Responsibility: The Disclosure-Performance Gap' Tourism Management 33 (6): 1544-53.

Freeman, R. 1984. Strategic Management: A Stakeholder's Approach. Boston, m A: Pitman.

Gond, J., S. Grubnic, C. Herzig, and J. Moon. 2012. 'Configuring Management Control Systems: Theorizing the Integration of Strategy and Sustainability'. Management Accounting Research 23:205-23.

Goodland, R. 1995. 'The Concept of Environmental Sustainability'. Annual Review of Ecology and Systematics 26:1-24.

Gubova, K., P. Richnak, L. Zendulka, and M. Pavlikova. 2017. 'Importance of Stakeholder Groups in Pursuit of Sustainable Development of Manufacturing Companies.' Journal of Interdisciplinary Research 7 (1): 1548.

Hagen, O. 2008. 'Seduced by their Proactive Image? On Using Auto Communication to Enhance CSR.' Corporate Reputation Review 11 (2): 13044.

Hahn, T., F. Figge, J. Pinkse, and L. Preuss. 2010. 'Trade-Offs in Corporate Sustainability: You Can't Have Your Cake and Eat it.' Business Strategy and the Environment 19 (4): 217-29.

Herremans, I. M., and J. A. Nazari. 2016. 'Sustainability Reporting Driving Forces and Management Control Systems.' Journal of Management Accounting Research 28 (2): 103-24.

Hickman, L. E., and J. Cote. 2019. 'CSR Reporting and Assurance Legitimacy: A Client-Assuror Dyad Investigation.' Journal of Applied Accounting Research 20 (4): 372-93.

Hooghiemstra, R. 200o. 'Corporate Communication and Impression Management: New Perspectives Why Companies Engage in Corporate Social Reporting.' Journal of Business Ethics 27 (1-2): 55-68.

Hopwood, A. G. 2009. 'Accounting and the Environment: Accounting.' Organisations and Society 34 (3-4): 433-9.

Jahdi, K. S., and G. Acikdilli. 2009. 'Marketing Communications and Corporate Social Responsibility (CSR): Marriage of Convenience or Shotgun Wedding.' Journal of Business Ethics 88 (1): 103-13.

Johnstone, L. 2018. 'Environmental Management Decisions in CsR-Based Accounting Research.' Corporate Social Responsibility and Environmental Management 25:1212-22.

Laguir, L., I. Laguir, and E. Tchemeni. 2019. 'Implementing CSR Activities through Management Control Systems: A Formal and Informal Control Perspective.' Accounting, Auditing \& Accountability Journal 32 (2): 531-55.

Lock, I. 2015. 'Analysing Sector-Specific CsR Reporting: Social and Environmental Disclosure to Investors in the Chemicals and Banking and 
Insurance Industry.' Corporate Social Responsibility and Environmental Management 22 (2): 113-28.

Lydenberg, S., J. Rogers, and D. Wood. 2020. From Transparency to Performance: Industry-Based Sustainability Reporting on Key Issues. N. p.: Harvard University.

Massung, E., D. Coyle, K. Carter, M. Jay, and C. Preist. 2013. 'Using Crowdsourcing to Support Pro-Environmental Community Activism.' In CHI'13: Proceedings of the SIGCHI Conference on Human Factors in Computing Systems, 371-80. New York: Association for Computing Machinery.

McLymont, R. 2018. 'CSR Reporting'. Network Journal 25 (3): 20-1.

Metcalfe, C. 1998. 'The Stakeholder Corporation.' Business Ethics: A European Review 7 (1): 30-6.

Morsing, M., and M. Schultz. 2006. 'Corporate Social Responsibility Communication: Stakeholder Information, Response and Involvement Strategies.' Business Ethics: A European Review 15 (4): 323-38.

Munoz-Torres, M. J., M. A. Fernandez-Izquierdo, L. Nieto-Soria, J. M. Rivera-Lirio, E. Escrig-Olmedo, and R. Leon-Soriano. 2009. 'S MES and Corporate Social Responsibility: The Perspective from Spanish Companies.' International Journal of Sustainable Economy 1 (3): 27088.

Nayak, U., and P. K. Patjoshi. 2020. 'Effect of CSR Contribution on Financial Performance: A Study on Automobile Companies of India.' International Journal of Modern Agriculture 9 (3): 981-9.

O’Riordan, L. 2010. 'Perspectives on Corporate Social Responsibility (CSR): Corporate Approaches to Stakeholder Engagement in the Pharmaceutical Industry in the $\mathrm{UK}$ and Germany.' PhD dissertation, Bradford University.

Parmar, B. L., R. E. Freeman, J. S. Harrison, A. C. Wicks, L. Purnell, and S. de Colle. 2010. 'Stakeholder Theory: The State of the Art.' Management Faculty Publications 99:1-62.

Quelch, J. A. 2004. 'ів м on Demand Community.' Case Study 9-504-103. Harvard Business School, Cambridge, MA.

Rinawiyanti, E. D., X. Huang, and S. As-Saber. 2020. 'Adopting Management Control Systems through CS R Strategic Integration and Investigating its Impact on Company Performance: Evidence from Indonesia.' Corporate Governance. https://doi.org/10.1108/CG-04-2020-0150.

Schonher, N., F. Findler, and A. Martinuzzi. 2017. 'Exploring the Interface of CSR and the Sustainable Development Goals.' Transnational Corporations 24 (3): 33-47.

Shnayder, L., and F. J. Rijnsoever. 2018. 'How Expected Outcomes, Stakeholders, and Institutions Influence Corporate Social Responsibility at 
Different Levels of Large Basic Needs Firms.' Business Strategy and the Environment 27:1689-707.

Simons, R. 2006. Levers of Organization Design: How Managers Use Accountability Systems for Greater Performance and Commitment. Boston, M A: Harvard Business School Press.

Spence, C. 2009. 'Social and Environmental Reporting and the Corporate Ego.' Business Strategy and the Environment 18:254-65.

Speziale, M. T., and L. Kloviene. 2014. 'The Relationship between Performance Measurement and Sustainability Reporting: A Literature Review.' Procedia: Social and Behavioral Sciences 156:633-8.

Stojanovic, A., I. Milosevic, S. Arsic, S. Urosevic, and I. Mihaljovic. 2020. 'Corporate Social Responsibility as a Determinant of Employee Loyalty and Business Performance.' Journal of Competitiveness 12 (2): 149-66.

Sweeney, L., and J. Coughlan. 2008. 'Do Different Industries Report Corporate Social Responsibility Differently? An Investigation through the Lens of Stakeholder Theory'. Journal of Marketing Communications 14 (2): 113-24.

United States Environmental Protection Agency. 2018. 'Greenhouse Gas Emissions from a Typical Passenger Vehicle.' https://www.epa.gov/ greenvehicles/greenhouse-gas-emissions-typical-passenger-vehicle.

Vieira, E. T. Jr. 2019. Public Relations Planning. New York: Routledge.

Winkler, H. 2010. 'Sustainability through the Implementation of Sustainable Supply Chain Networks.' International Journal of Sustainable Economy 2 (3): 293-309. 